\title{
KENDALI TEGANGAN DAN FREKUENSI BERJANGKAH UNTUK IC HEF4752 SEBAGAI PENGATUR TEGANGAN DAN FREKUENSI TIGA FASA 30 VOLT
}

\author{
Tisna Prihadiyanti Kusmaningrum ${ }^{1}$, Sunomo ${ }^{2}$ \\ 1,2 Jurusan Pendidikan Teknik Elektro FT UNY \\ Email: tisna.prihardiyanti2015@student.uny.ac.id
}

\begin{abstract}
Goal of this research is done to regulate the voltage and frequency of the three-phase voltage source with a range of 18.8 - 20.7 volts to distribute three phase motors in the power electronics practice. Use of low voltage aimed at securing measuring devices or practitioner of the possibility of error that jeopardize. Step of the research, namely the concept of the design, needs analysis, identification of tools and materials, manufacturing of hardware and software as well as making tools. Designed system consists of four parts : ( 1) power supply, ( 2 ) control circuit IC HEF4752, ( 3 ) minimum system, ( 4 ) strand motor driver. Based on the obtained test voltage range $18.8-20.7$ volt and frequency $17.24-62.5 \mathrm{~Hz}$ in six positions. Control voltage and frequency signal is obtained by changing - change two resistors on the two oscillators HEF4047 by changing the logic of dikeluaran 4067 based microcontroller that controls the output of the three-phase PWM IC HEF4752 to produce the effect of changes in voltage and frequency simultaneously.
\end{abstract}

Keywords: IC HEF 4752 , three phase motor, speed regulator, voltage and frequency

\section{ABSTRAK}

Tujuan penelitian ini untuk mengatur tegangan dan frekuensi sumber tegangan tiga fasa dengan rentang 18.8 - 20.7 volt untuk mencatu motor tiga fasa dalam praktek elektronika daya. Pengunaan tegangan rendah bertujuan untuk mengamankan alat ukur maupun praktikan dari kemungkinan terjadi kesalahan yang membahayakan. Tahapan penelitian, yakni konsep rancangan, analisa kebutuhan, identifikasi alat dan bahan, pembuatan perangkat keras dan perangkat lunak serta pembuatan alat. Sistem yang dirancang terdiri dari empat bagian: (1) catu daya, (2) rangkaian kendali IC HEF4752, (3) sistem minimum, (4) untai driver motor. Berdasarkan pengujian diperoleh rentang tegangannya $18.8-20.7$ volt, dan frekuensinya $17.24-62.5 \mathrm{~Hz}$ dalam enam posisi. Sinyal pengatur tegangan dan frekuensi diperoleh dengan mengubah-ubah dua resistor pada dua buah osilator HEF4047 dengan cara mengubah logika dari dikeluaran 4067 berdasarkan keluaran mikrokontroler yang mengendalikan IC PWM tiga fasa HEF4752 untuk menghasilkan efek perubahan tegangan dan frekuensi secara serentak.

Kata kunci: IC HEF 4752, motor tiga fasa, pengatur kecepatan, tegangan dan frekuensi

\section{PENDAHULUAN}

Di dunia industri motor listrik digunakan sebagai tenaga searah dalam proses produksi. Jenis motor listrik yang digunakan umumnya motor induksi tiga fasa karena konstruksinya yang sederhana dan ukurannya yang relatif lebih kecil untuk daya keluaran sama, dibandingkan dengan motor listrik satu fasa. Motor bolak-balik tiga fasa bekerja dengan memanfaatkan gerakan vektor tegangan sumber untuk menimbulkan gaya putar pada rotornya. Pada motor bolak-balik satu fasa, untuk menghasilkan gerak putar penambahan komponen kapasitor untuk menentukan geseran fasa antara belitan utama dan belitan bantu agar dapat menghasilkan gerak putar. Motor induksi dapat dikendalikan secara manual maupun secara semi otomatis menggunakan kontaktor magnit untuk mengoperasikan tegangan fasa pada kecepatan yang berbeda-beda. Motor 
bolak balik membutuhkan frekuensi tegangan yang berbeda-beda pula agar diperoleh momen putar yang sama pada kecepatan yang berbeda digunakan pengendalian frekuensi dan tegangannya yang dikenal dengan Variable Voltage Variable Frequency (VVVF). Variable Voltage Variable Frequency merupakan pengendali kecepatan motor dengan mengatur tegangan dan frekuensi secara serentak mengunakan PWM (Pulse Width Modulation).

PWM yang digunakan adalah IC HEF4752VP untuk dapat bekerja, IC HEF4752VP yang merupakan PWM tiga fasa yang membutuhkan dua IC pembangkit frekuensi yaitu IC HEF4047B. Frekuensi dan tegangan dapat diatur secara serentak dibutuhkan pengaturan otomatis melalui suatu mekanisme gerak dengan bantuan kendali mikrokontroller. Kendali motor tiga fasa yang memanfaatkan IC HEF4752VP telah dibuat oleh Chandra Mukti (2013), Nanda Cristy (2013), dan Nurrohman (2014), namun, ketiganya masih menggunakan pengaturan terpisah untuk tegangan dan frekuensinya. Penelitian ini, kedua pengaturan dijadikan satu dengan bantuan kendali mikrokontroler. Pengaturan HEF4752VP dengan kendali mikrokontroler juga telah dibuat oleh Wulan Ramadani (2015) dalam empat pengaturan motor yakni stop, low speed, medium speed, dan high speed. Melalui penelitian ini, pengaturan dilakukan lebih halus, menggunakan enam pengaturan. Selain itu pada keluaran tiga fasanya menggunakan tapis RC pada MOSFET untuk meminimalkan tegangan paku (spike) yang timbul.

\section{METODE}

Penelitian ini memiliki beberapa proses, yakni mulai dari konsep perancangan, analisis kebutuhan bahan, identifikasi alat dan bahan, pembuatan, serta pengujian.

\section{Perancangan}

Tahapan awal yang sangat penting dalam pembuatan suatu alat adalah konsep perancangan. Suatu alat dapat bekerja dengan baik sesuai dengan fungsinya apabila telah di rancang dengan matang sebelum proses pembuatan. Perancangan suatu alat dapat dilakukan dengan berbagai cara, misalnya saja dengan menggambarkan diagram blok, sketsa rangkaian, maupun spesifikasi alat yang akan dibuat.

Sumber tegangan bolak balik 3 fasa 30 volt sebagai pemasok teganan ke beban maupun rangkaian kendali. Rangkaian kendali terdiri dari, rangkaian catu daya, rangkaian PWM yang menggunakan IC HEF4752 sebagai kemudi dan rangkaian kendali motor. Rangkaian kendali membutuhkan tegangan bolak balik sehingga sebelum tegangan disuplay pada rangkaian kendali, tegangan disearahkan terlebih dahulu pada rangkaian catu daya yang akan menghasilkan tegangan searah sebesar 12 VDC.

\section{Analisis Kebutuhan}

Pembuatan kendali tegangan dan frekuensi berjangkah untuk IC HEF4752VP sebagai pengatur tegangan dan frekuensi 3 phasa 30 volt membutuhkan peralatan serta bahan sebagai berikut : (1) catu daya sebagai suplai tegangan agar rangkaian dapat bekerja, (2) rangkaian kendali IC HEF4752VP, (3) sistem minimum ATMega16 sebagai pengenali rangkaian, (4) bahasa pemrograman untuk menjalankan microcontroler, (5) pengendali tegangan dan frekuensi motor, dan (6) tempat alat atau casing.

\section{Pembuatan Sistem}

Pembuatan sistem meliputi pembuatan hardware dan software. Pembuatan hardware, Pembuatan hardware ini dimulai dengan perancangan desain PCB, kemudian melarutkan PCB hingga memasang komponen pada PCB.

$$
\text { Pembuatan software, untuk }
$$

menjalankan sebuah mikrokontroler dengan baik dibutuhkan sebuah program, program tersebut membutuhkan sebuah software pendukung untuk membuat Bahasa pemrogramannya ataupun pengunduhan Bahasa program tersebut. Perangkat lunak yang digunakan dalam pembuatan program ini adalah 
CodeVision AVR dengan bahasa pemrograman Bahasa C.

\section{Pengujian}

Pengujian Alat merupakan proses untuk mengetahui suatu alat bekerja dengan baik atau tidak. Pengujian yang dilakukan meliputi :

(1) uji fungsional, pengujian ini dilakukan dengan cara menguji setiap komponen apakah bekerja dengan baik atau tidak berdasarkan karakteristik dan fungsi dari masing-masing komponen. Hal ini bertujuan agar alat berfungsi dengan baik dan tidak memiliki permasalahan. (2) uji unjuk kerja, uji unjuk kerja alat dilakukan dengan cara mengamati cara kerja alat, yang perlu diamati adalah: sistem minimum, driver motor, dan rangkaiaan filter.

\section{HASIL DAN PEMBAHASAN}

Hasil pengujian dan pengukuran dilakukan dengan menggunakan beberapa alat ukur.

Pertama, Hasil pengujian dan pengukuran dilakukan pada keluaran catu daya menggunakan multimeter. Hasil pengukuran dapat dilihat pada tabel 1 berikut.

Tabel 1. Hasil Pengukuran Tegangan IC Regulator LM7805

\begin{tabular}{|c|l|c|c|}
\hline No. & Pengukuran & $\begin{array}{c}\text { Teangan Masukan Searah } \\
\text { (Volt) }\end{array}$ & $\begin{array}{c}\text { Tegangan Keluaran Searah } \\
\text { (Volt) }\end{array}$ \\
\hline 1. & Tanpa Beban & 12 & 5 \\
\hline 2. & Mengunakan Beban & 12 & 5 \\
\hline
\end{tabular}

Tabel 4. Logika pada Mikrokontroler

\begin{tabular}{|c|c|c|c|c|c|c|c|}
\hline \multirow{2}{*}{ No- } & \multicolumn{5}{|c|}{ Masukan } & \multicolumn{3}{c|}{ Keluaran } \\
\cline { 2 - 8 } & Port BO & Port B 1 & Port B2 & Port B3 & Port A1 & Port A2 & Port A3 \\
\hline 1 & 1 & 1 & 1 & 1 & 0 & 0 & 0 \\
\hline 2 & 1 & 0 & 1 & 1 & 1 & 0 & 0 \\
\hline 3 & 1 & 1 & 0 & 1 & 0 & 1 & 0 \\
\hline 4 & 1 & 0 & 0 & 1 & 1 & 1 & 0 \\
\hline 5 & 1 & 1 & 1 & 0 & 0 & 0 & 1 \\
\hline 6 & 1 & 0 & 1 & 0 & 1 & 0 & 1 \\
\hline
\end{tabular}

Hasil pengujian pengukuran tegangan IC regulator LM7805 tidak terdapat presentase eror karena tegangan masukan saat tanpa beban dan mengunakan beban adalah sama, begitu jua dengan tegangan keluarannya.

Kedua, Hasil pengujian pengukuran tegangan mikrokontroler tidak ada presentase error, hal tersebut dapat dilihat pada tabel $2 \mathrm{di}$ bawah ini,bahwa tidak ada perbedaan antara tegangan masukan dengan tegangan keluaran.

Tabel 2. Pengujian Tegangan Mikrokontroler

\begin{tabular}{|l|c|c|}
\hline No & $\begin{array}{c}\text { Tegangan Masukan } \\
\text { (Volt) }\end{array}$ & $\begin{array}{c}\text { Tegangan Keluaran } \\
\text { (Volt) }\end{array}$ \\
\hline 1. & 5 & 5 \\
\hline
\end{tabular}

Ketiga, pengujian tegangan pada IC 4067 ditunjukkan pada tabel 3.

Tabel 3. Pengujian Tegangan pada IC 4067

\begin{tabular}{|l|c|c|}
\hline No & $\begin{array}{c}\text { Tegangan Masukan } \\
\text { (Volt) }\end{array}$ & $\begin{array}{c}\text { Tegangan Keluaran } \\
\text { (Volt) }\end{array}$ \\
\hline 1. & 12 & 11,8 \\
\hline
\end{tabular}

Hasil pengukuran teganngan masukan adalah $12 \mathrm{~V}$ dan teganagan pada IC 4067 adalah 11,8 V sehingga terjadi presentase error sebesar:

Error=(tegangan masukan-tegangan keluaran) $\mathrm{X}$ $100 \%$

$$
\begin{aligned}
& =(12-11,8) \times 100 \% \\
& =2 \%
\end{aligned}
$$

Keempat, pengujian logika keluaran Mikrokontroler. Hasil pengujian logika keluaran mikrokontroler dapat dilihat pada Tabel 4 dibawah ini. 
Hasil pengujian keluaran mikrokontroler sesuai dengan program yang telah dibuat, seperti pada tabel 5.

Tabel 5. Pengujian LCD

\begin{tabular}{|c|c|c|}
\hline No. & Pengujian Tombol & Tampilan LCD \\
\hline 1 & 1 & Posisi 1 \\
\hline 2 & 2 & Posisi 2 \\
\hline 3 & 3 & Posisi 3 \\
\hline 4 & 4 & Posisi 4 \\
\hline 5 & 5 & Posisi 5 \\
\hline 6 & 6 & Posisi 6 \\
\hline
\end{tabular}

Kelima, pengujian logika pada untai kendali motor dilakukan dengan mengecek logika IC 4067, pada penelitian ini logika pada IC 4067 dikendalikan oleh program dari mikrokontroler, akan tetapi logika pada IC 4067 berkebalikan dengan logika dari mikrokontroler. Hal ini dikarenakan adanya komponen transistor common emitor sebagai saklar yang terdapat pada keluaran mikrokontroler, hal ini dilakukan karena IC 4067 membutuhkan tegangan masukan sebesar 12 volt sedangkan tegangan keluaran dari mikrokontroler hanya 5 volt, sesuai dengan karakteristik dari transistor common emitor yaitu sinyal berbalik fasa 180 derajat terhadap sinyal masukan, jadi apabila sinyal masukan mikrokontroler logika 0 maka sinyal keluaran pada transistor adalah 1 , sinyal keluaran tersebut menjadi masukan pada IC 4067. Pengukuran tegangan pada saklar IC 4067 dapat dilihat pada tabel 6 .

Tabel 6. Pengukuran Tegangan pada Saklar IC 4067

\begin{tabular}{|c|c|c|c|c|c|c|c|c|}
\hline \multirow{2}{*}{ No } & \multicolumn{4}{|c|}{ Logika pada IC 4067 } & \multicolumn{4}{c|}{ Tegangan pada IC 4067 (Volt) } \\
\cline { 2 - 9 } & A & B & C & D & A & B & C & D \\
\hline 1 & 0 & 0 & 0 & 0 & 11,8 & 11,8 & 11,8 & 0 \\
\hline 2 & 1 & 0 & 0 & 0 & 0 & 11,8 & 11,8 & 0 \\
\hline 3 & 0 & 1 & 1 & 0 & 11,8 & 0 & 0 & 0 \\
\hline 4 & 0 & 0 & 1 & 0 & 11,8 & 11,8 & 0 & 0 \\
\hline 5 & 1 & 1 & 0 & 0 & 0 & 0 & 11,8 & 0 \\
\hline 6 & 1 & 0 & 1 & 0 & 0 & 11,8 & 0 & 0 \\
\hline
\end{tabular}

Keenam, Pengamatan gelombang Frekuensi keluaran IC 4047 dengan ground osiloskop di titik tegangan searah. Pada pengujian gelombang frekuensi pengamatan dilakukan menggunakan osiloskop. Osiloskop yang digunakan adalah osiloskop 3 fasa berfasilitas empat kanal sehingga bentuk gelombang dapat terlihat lebih jelas. Pengamatan ini dilakukan untuk mengetahui lebar pulsa keluaran IC 4047 pada setiap posisi putaran motor. Pengamatan dilakukan pada kaki 12 (FCT), 4 (RCT), 17 (VCT), dan 6 (OCT). Posisi probe osiloskop kanal 1 FCT, kanal 2 RCT, kanal 3 VCT, dan kanal 4 OCT. Hasil 
pengamatan dapat dilihat dari gambar 1 yaitu frekuensi keluaran IC 4047 posisi 1dan tabel 7 adalah hasil pengamatan frekuensi masukan IC HEF4752VP.

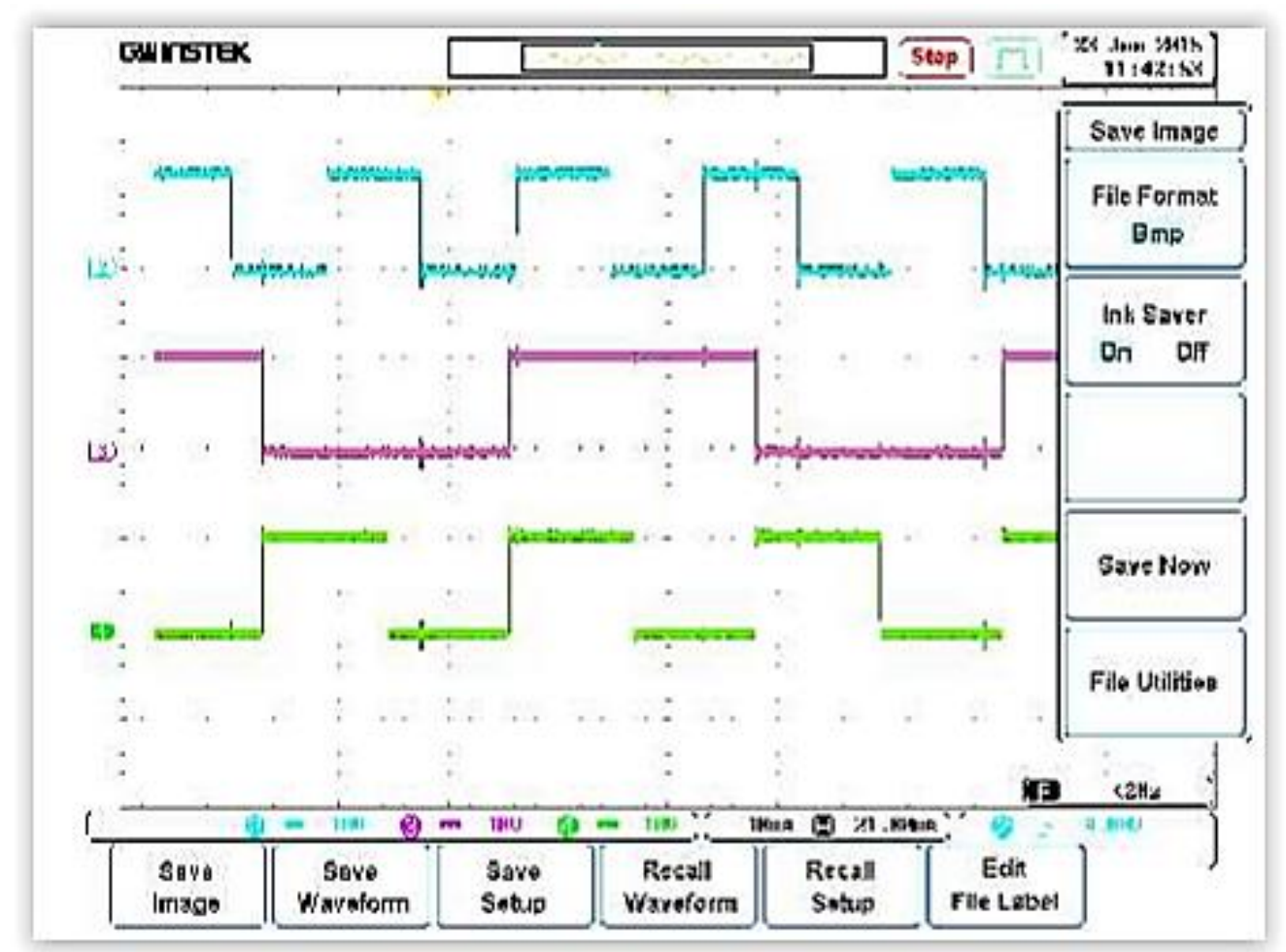

Gambar 1. Frekuensi Keluaran IC 4047 Posisi 1

Tabel 7. Hasil Pengamatan Frekuensi Masukan IC HEF4752VP

\begin{tabular}{|c|c|c|c|c|}
\hline \multirow{2}{*}{ Posisi } & \multirow{2}{*}{ Nombol } & \multicolumn{3}{|c|}{ Posisi Probe Osiloskop } \\
\cline { 3 - 5 } & \multirow{2}{*}{ Gambar } & $\begin{array}{c}\text { Kanal 2 } \\
(\mathrm{kHz})\end{array}$ & $\begin{array}{c}\text { Kanal 3 } \\
(\mathrm{kHz})\end{array}$ & $\begin{array}{c}\text { Kanal 4 } \\
(\mathrm{kHz})\end{array}$ \\
\hline 1 & 23 & 55.5 & 22.2 & 45.45 \\
\hline 2 & 24 & 83.3 & 32.25 & 64.5 \\
\hline 3 & 25 & 90.90 & 32.25 & 64.5 \\
\hline 4 & 26 & 100 & 33.3 & 66.6 \\
\hline 5 & 27 & 142.85 & 32.24 & 64.5 \\
\hline 6 & 28 & 166.67 & 31.25 & 62.5 \\
\hline
\end{tabular}


Ketujuh, pengamatan gelombang keluaran IC HEF 4752 VP. Pengamatan gelombang frekuensi dan tegangan pada beban simulasi motor 3 fasa dengan tegangan antara 18 - 30 volt dilakukan dengan menggunakan osiloskop digital tiga fasa empat kanal. Pengamatan ini dilakukan untuk mengetahui lebar dan tinggi gelombang pada setiap pengaturan posisi motor. Pengamatan dilakukan pada posisi kaki fasa $\mathrm{R}, \mathrm{S}$, dan T. Posisi probe osiloskop kanal 1 pada posisi R, posisi probe osiloskop kanal 2 pada posisi $\mathrm{S}$, dan posisi probe kanal 3 pada posisi T. Hasil pengamatan dapat dilihat dari gambar 2 yaitu frekuensi keluaran beban posisi 1 dan tabel 8 hasil pengamatan frekuensi keluaran beban.

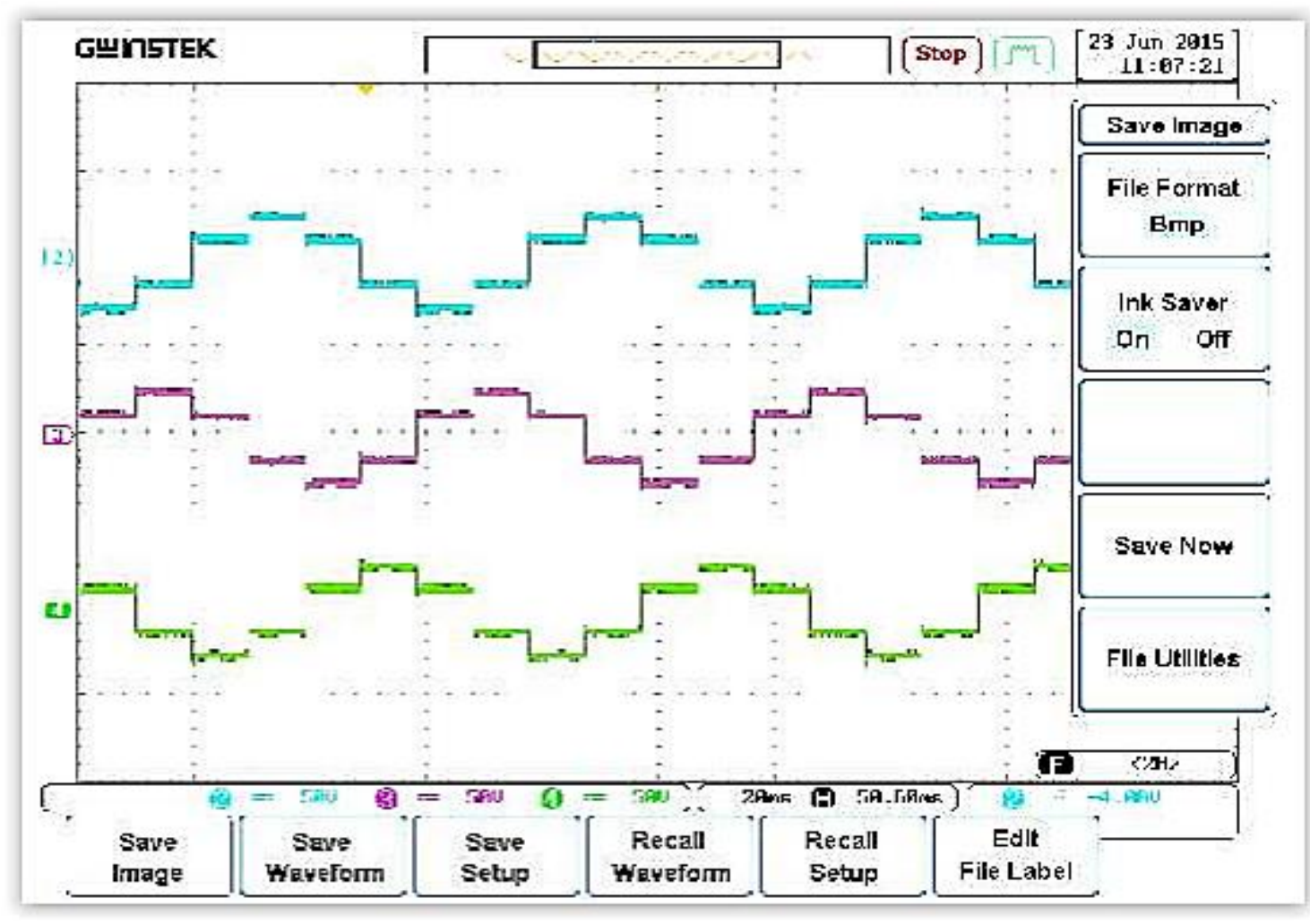

Gambar 2. Frekuensi Keluaran Beban Posisi 1

Tabel 8. Hasil Pengamatan Frekuensi Keluaran Beban

\begin{tabular}{|c|c|c|}
\hline Posisi Tombol & No. Gambar & Frekuensi (Hz) \\
\hline 1 & 29 & 17.24 \\
\hline 2 & 30 & 25 \\
\hline 3 & 31 & 26.31 \\
\hline 4 & 32 & 31.25 \\
\hline 5 & 33 & 43.47 \\
\hline 6 & 34 & 62.5 \\
\hline
\end{tabular}


Kedelapan, pengukuran tegangan dan kecepatan motor keluaran IC HEF4752VP. Pengukuran tegangan keluaran IC HEF4752 dilakukan dengan multimeter analog, digital, dan tacho meter, hasil pengukuran tegangan dapat dilihat pada tabel 9 dan tabel 10 .

Tabel 9. Pengukuran Tegangan Keluaran IC HEF4752VP

\begin{tabular}{|c|c|c|c|}
\hline Posisi Tombol & Multimeter Analog (Volt) & Frekuensi (Hz) & Kecepatan Motor (Rpm) \\
\hline 1 & 18,8 & 17.24 & 500 \\
\hline 2 & 19.1 & 25 & 766 \\
\hline 3 & 19.5 & 26.31 & 798 \\
\hline 4 & 20 & 32.51 & 908 \\
\hline 5 & 10 & 43.47 & 1263 \\
\hline 6 & 20.7 & 62.5 & 1840 \\
\hline
\end{tabular}

Tabel 10. Besar Resistor pada Masukan 4047

\begin{tabular}{|c|c|c|}
\hline Posisi Tombol & $\begin{array}{c}\text { Resistor Tegangan } \\
(\mathrm{k} \Omega)\end{array}$ & $\begin{array}{c}\text { Resistor Frekuensi } \\
(\mathrm{k} \Omega)\end{array}$ \\
\hline 1 & 55 & 30 \\
\hline 2 & 40 & 35 \\
\hline 3 & 35 & 40 \\
\hline 4 & 35 & 45 \\
\hline 5 & 40 & 55 \\
\hline 6 & 40 & 65 \\
\hline
\end{tabular}

\section{Pembahasan}

Dari hasil pengamatan gelombang masukan IC HEF4752VP pada Tabel 7 dapat diketahui bahwa rentang frekuensi pada kaki $\mathrm{FCT}=55.5 \mathrm{kHz}$ sampai $=166.67, \mathrm{VCT}=22.2$ $\mathrm{kHz}$ sampai $33.3 \mathrm{kHz}$, dan OCT $=44.4 \mathrm{kHz}$ sampai $33.3 \mathrm{kHz}$. Besar nilai frekuensi dipengaruhi oleh besar kecilnya nilai resistor serta kapasitor penentu frekuensi pada IC
HEF4047B. semakin besar hambatan pada IC HEF4047B maka semakin kecil frekuensinya, sebaliknya jika nilai hambatan semakin kecil maka nilai frekuensi semakin besar.

Dari hasil pengamatan tabel 8 rentang nilai frekuensi pada beban berkisar antara 17.24 sampai $62.5 \mathrm{~Hz}$, sedangkan nilai tegangan dapat dilihat pada Tabel 9 berkisar antara 18.8 sampai 20.7 Volt. Besar nilai frekuensi akan 
mempengaruhi kecepatan motor. Nilai kecepatan motor berbanding lurus dengan nilai frekuensi, dapat dilihat pada tabel 9 semakin besar frekuensi dan tegangan semakin besar pula kecepatan motor yang dihasilkan.

\section{SIMPULAN}

Setelah melakukan uji coba dan pembahasan dapat disimpulkan bahwa alat yang dibuat dapat mengubah nilai tegangan dan frekuensi secara serentak dan secara tidak langsung mempengaruhi kecepatan motor bolak balik tiga fasa pada enam posisi. Rentang tegangan yang diperoleh 18.8 - 20.7 Volt, rentang frekuensi $17.24-62.5 \mathrm{~Hz}$, dan rentang kecepatan motor $500-1840$ Rpm. Pengaturan nilai tegangan dan frekuensi ini menggunakan mikrokontroler yang telah deprogram menggunakan perangkat lunak kemudian keluaran mikrokontroler mengendalikan IC 4067, dari keluaran 4067 digunakan untuk mengendalikan IC 4047 sebagai pembangkit frekuensi dan tegangan, kemudian IC 4047 sebagai osilator mengendalikan IC PWM tiga fasa HEF4752 untuk menghasilkan efek perubahan tegangan dan frekuensi secara serentak. Besarnya nilai tegangan dan frekuensi dipengaruhi oleh besarnya hambatan pada IC pembangkit frekuensi dan pembangkit tegangan yang dihasilkan. Sebaliknya jika hambatan semakin kecil makan nilai tegangan dan frekuensi semakin besar.

\section{DAFTAR RUJUKAN}

Bayu Aji Nugroho. 2014. Mesin Induksi Tiga Fasa. Makalah. Sekolah Tinggi Teknik PLN Jakarta.

Nur Rohman Eko Nugroho. 2014. Konverter Tegangan dan Frekuensi Tiga Fasa Variabel dengan Rangkaian Kemudi IC HEF4752VP. Proyek Akhir. Universitas Negeri Yogyakarta.

Sunyoto. 1993. Mesin Arus Bolak-Balik .Yogyakarta :IKIP Yogyakarta.

Wulan Ramadani. 2015. Pengatur Potensio Ganda Berjangkah Tanpa Gerakan Mekanik Dengan Mikrokontroler ATMega 8535 untuk Modul Pembelajaran Pengoperasian Motor Arus Bolak - Balik (AC) Tiga Fasa. Proyek Akhir. Universitas Negeri Yogyakarta. 